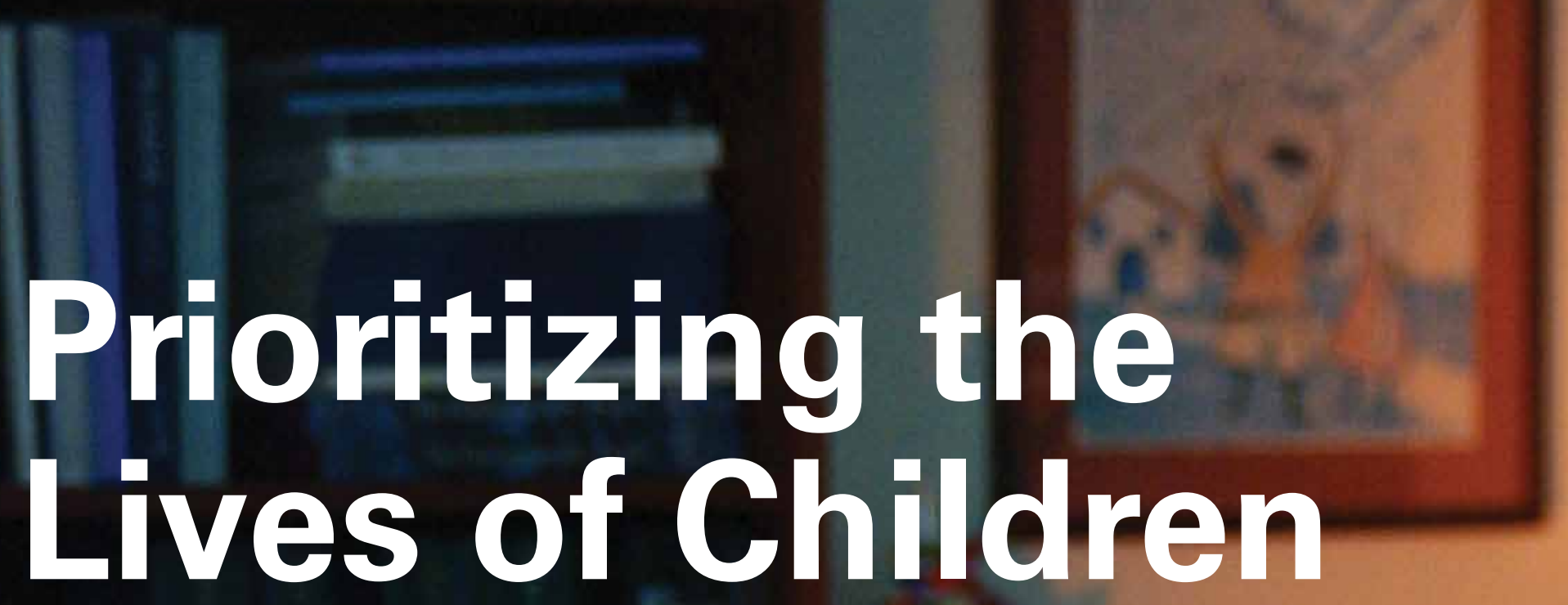

Mary Jo Haddad, in conversation with Alan Guttmacher

I n August 2011, I had the pleasure of conducting a lengthy interview with Alan E. Guttmacher, the director of the Eunice Kennedy Shriver National Institute of Child Health and Human Development (NICHD), in Bethesda, Maryland. Over his long and impressive career, Guttmacher has proven himself to be one of the world's leading pediatricians and medical geneticists.

The insights and observations Guttmacher shared during our conversation resonate profoundly with many of the essays we have lined up for the fourth issue of our Child Health in Canada series. It seems fitting, therefore, to begin this issue on Child Health Promotion not with a traditional article but, instead, with this wide-ranging and illuminating conversation, which sets the thematic stage for much of what follows.

\title{
- Mary Jo Haddad
}

Chief Executive Officer

The Hospital for Sick Children, Toronto

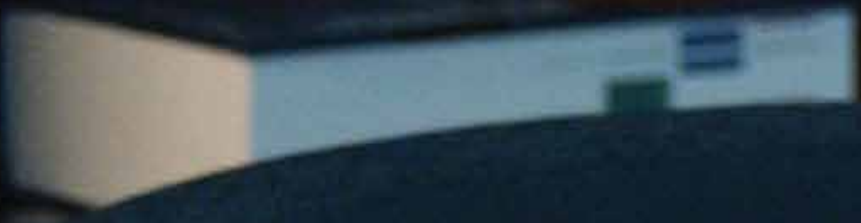




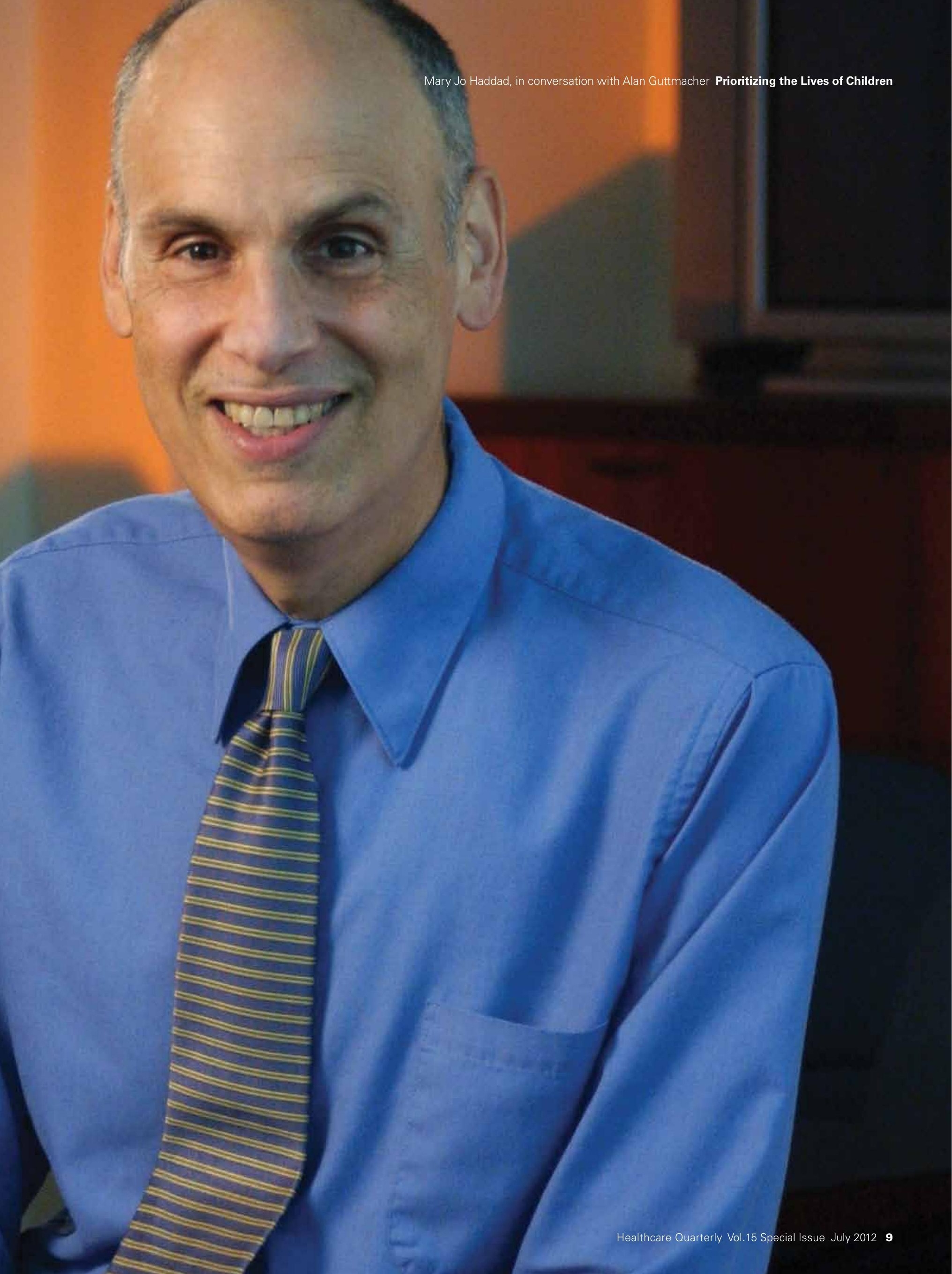


MJH: I would like to begin our conversation with a bit of an introduction into who Alan E. Guttmacher is. Would you describe a little about your past, the position you hold today and the value your role brings to a broad dialogue in the United States on children's health?

AG: I am by training a pediatrician and medical geneticist, although my other lens that I use to think about child health is derived from the fact that before I went into medicine, I taught middle school for a couple of years. I first got interested in pediatrics through an interest in kids' problems with learning and with what was -in those days - diagnosed as dyslexia in several of my students.

\section{It's been shown repeatedly that investments in children's health pay off incredibly well in the long run.}

That experience drew my attention to how kids learn, which got me interested in pediatrics, which led to my career in children's healthcare and then to my specialization in medical genetics. After my fellowship and training period, I spent about 12 years at the University of Vermont (UVM), where I was primarily a clinical geneticist. And I was also founding director of UVM's Pediatric Intensive Care Unit.

Then, about a dozen years ago, I was invited to come down to the National Institutes of Health (NIH) to work at the National Human Genome Research Institute (NHGRI), which is the NIH institute charged with leading the Human Genome Project. The NHGRI's director at the time was Francis Collins, and he wanted to have someone who was focused on integrating genomicsrelated knowledge; essentially, to think about the questions, What in the world does the genome sequence mean in terms of human health? and, especially, How do we use it in healthcare?"

I eventually became the deputy director and then the acting director of NHGRI, and for about a year now, I have been serving as the institute's permanent director. This role gives me a great opportunity to be engaged with and to have a positive influence on a lot of issues about which I happen to care deeply, both personally and professionally. NHGRI has a wonderful mission.

MJH: Alan, those of us working in children's health are very focused on the state of children's health and the challenges within children's health, as well as on the opportunities and the progress made to date. From your vantage point, would you share with us your thoughts on the progress we've made collectively in children's health and on where you think we absolutely need to focus as a society, as providers and as governments as we look at how to improve children's health at a faster rate?

AG: Answering that question depends partly on the time frame one considers. In some areas of children's health, we've made progress that is so dramatic that former problems are virtually gone from our thinking. They have slipped off the radar, so we don't have much opportunity to pat ourselves on the back.

For instance, for the vast majority of the world, polio has essentially disappeared. That's certainly a dramatic change. And the case is similar with many infectious diseases. When I was an intern and pediatrics resident, not that long ago, we saw an incredible amount of Haemophilus influenzae ("H-flu"). If you ask health officers today about $\mathrm{H}$-flu, they give you a quizzical look and say, "Gee, I've read about it in a textbook." They have no experience treating patients with $\mathrm{H}$-flu, whereas I admitted lots of patients with $\mathrm{H}$-flu meningitis and saw the devastating effects it could have.

If you talk about what pediatric practice was in the past, so much of what was treated and worried about were infectious diseases. Clearly, that's still a major issue in much of the developing world. But, even there, we're beginning to make some real inroads.

Other areas have changed as well. Acute lymphoblastic leukemia in kids used to be, essentially, a death sentence. Now, it is something that is usually cured in childhood. That doesn't mean we shouldn't worry about some of the toxicities of some of the medications we use to treat lymphoblastic leukemia, and it doesn't mean some children don't still die from it. But, again, in our lifetime, we've witnessed a dramatic change. In terms of sudden infant death syndrome (SIDS), the incidence rate has been knocked down by $50 \%$ over the past 20 years, simply by repositioning children so that they are sleeping on their backs instead of on their tummies.

Of course, while we've done a much better job dealing with infectious diseases, injury now actually occupies a larger proportion of serious morbidity and mortality in childhood than it used to. It's not that we're doing a worse job with injury in general than before; we're actually doing a better job (for example, through the more pervasive use of seatbelts and bicycle helmets for kids). But, since we've removed a lot of the other problems that used to affect kids, injury is relatively a much larger concern than before.

MJH: In light of all you have said about improvements, but also considering the challenges that remain, I'm interested to know how you would replace $X$ in the following statement: "If only we could focus on $X$, it would have such a profound impact on improving children's health."

AG: I think one $X$ would certainly be prematurity. If we could do a better job in terms of preventing preterm births, that's one way we could have a real impact on kids' lives, families and 
communities. Again, this is clearly an area in which we have made some good progress; but, in fact, in some ways you could argue it's more of a problem than ever before. Because we're able to keep kids alive who are born earlier and earlier, those children live to have various sequelae of their early birth. And considering kids who have preterm births later in gestation, we know that, while on an individual level there might not be a huge impact, from a public health point of view the kids that are born at 37 weeks would do better if they had been born at 39 weeks.

\section{MJH: Is that about public health per se or do you think it's a combination of issues and factors?}

AG: I think it's really a combination. Part of the concern is that we still don't understand all the factors that combine to cause preterm birth. We need to understand all the pathways and causes - biological, environmental and cultural.

One of the cultural factors we often confront is the culture of obstetrics. That's one of the causes of preterm birth, in terms of the significantly higher rate of Caesarean sections in North American than was the case a couple of decades ago. Sometimes Caesarean delivery is clearly indicated for the health and wellbeing of a pregnant woman or her fetus. But, it's clear that there are times when the decision to perform a C-section really is more of a cultural than strictly medical one.

We also require education and public health campaigns (some of which we have); and, once we fully understand the causes of preterm birth, we must try to intervene so that those causes can be prevented. And even if the causes persist, we must be able to intervene to lessen their impact and either help women avoid preterm births or to at least move delivery later into pregnancy.

I think the preterm birth issue provides a good model for so much of children's health: because it involves multiple factors, it's not going to be as easy to deal with preterm births as it was with immunization. There won't be a shot that prevents it. We'll have to do more complex things.

To return to immunization, though, one of the things that I certainly worry about is that even though immunization made a larger impact on kids' lives than anything else that happened in the past century, immunization rates in some places are actually declining. That's because, I believe, we - as health and public health communities - have not done as good or as forceful a job as we need to do in order to convince parents that immunization is in the best interests of their children. So, even with issues with which we have been successful, we can't rest on our laurels.

MJH: Many of us involved in healthcare or who work with children have a good grasp of the complexities of systems and outcomes. There are so many competing priorities in healthcare, regardless of what country you're in or what societal challenges one might have. When we talk about health and healthcare, we recognize a multitude of challenges - be they access to care or the poor health of populations or value for money of the services we're providing. What do you believe makes the strongest case for supporting investments in children's health?

AG: I think it's a number of things. One can argue, simply, the moral point: we have a duty to take care of kids, who can't take care of themselves. But, if you get beyond the moral argument to an economic one, it's been shown repeatedly that investments in children's health pay off incredibly well in the long run. If you prevent a health event in a child that would otherwise lead to that child being disabled in some way, you will have had an

\section{I want anticipatory guidance to be about the next 60 years of a person's life.}

effect that will impact over decades and decades in terms of that child's ability to function fully in society. He will be able to earn an income, to pay taxes rather than be supported by the state, to contribute his skills to the nation's economy and so forth.

I think one of the real new opportunities in children's health in the coming 10 or 20 years is going to be, for the first time, having tools that allow us to realize the ancient idea that the child is father of the man and mother of the woman. For a long time, we've acted as though there is "children's health" and then, as long as you get children somehow safely through childhood, some kind of switch goes off and a few years later they show up as adults. In fact, however, we're learning more and more about how health in childhood really has an impact on lifelong health. Very early life experiences, influences etc. have an effect not just on an individual's personality but on, for example, the person's risk of having chronic obstructive pulmonary disease or heart disease as an adult.

More and more, we're learning about things in childhood such as the role of epigenetics or other phenomena where the nature of one's adult health is largely influenced or even set in childhood. One of the really intellectually exciting and important developments, again over the next decades, will be using the genome sequence. That will enable us to understand epigenetics and other related phenomena in order to comprehend how child health and child experience lead to adult health and well-being. It will also help us to plan various kinds of interventions in childhood that will affect long-term health.

One of the things I like to talk about is "anticipatory guidance" as a major part of pediatrics. One could argue that, because we're now dealing better with infectious diseases, anticipatory guidance has grown in importance. For pediatricians, it is taking on a larger role in terms of the contributions they can make to the lives of their patients and their patients' families. That's great, but I also look forward to the day when antici- 
patory guidance is not simply about the next six weeks or six months or even six years of a child's life. I want anticipatory guidance to be about the next 60 years of a person's life.

Pediatricians today clearly don't have the tools to do this in the primary care setting; I'm hopeful, however, that we will in the not-too-distant future. Pediatricians will, based upon knowledge

\section{We need to continue to be thinking ahead about how morbidity and mortality change, and also about how to seize opportunities to intervene in those changes.}

of a kid's genome sequence and various environmental influences in the kid's life, be able - in an individualized way - to talk with a child and the child's parents about various kinds of things that could be done in childhood to increase (not guarantee) the odds for good health well into adulthood. That will be, I think, a wonderful day in terms of what we can do for our patients.

\section{MJH: It also will challenge us as systems leaders} to think about what it will take, what should look different, what should be different in terms of the way we deliver services, the way we deliver care, the silos that we currently have between adult care and pediatric care or between primary care and specialty care.

AG: We're already seeing such thinking in a more limited way as we attempt to deal with patients who used to die from their diseases but now live into adulthood. Who do we hand those patients off to? Whether it be patients with cystic fibrosis or sickle cell disease or Down syndrome, what happens when those kids become adults and there aren't very many internists who have ever had experience dealing with such diseases?

We've already been challenged by that somewhat; but you're absolutely right that if the vision I'm talking about becomes reality, which I think it will, then it's going to be even more challenging. How do we construct systems to deal with this, and how do we even pay for it?

\section{MJH: I'm thinking about many of the diseases you} spoke about, for example, congenital heart disease. In that area, we're seeing important changes that are required at the adult cardiovascular surgical level; so, how do we think about congenital heart disease or congenital disease in general in a perhaps more integrative way? In order to do so, the care models and our clinicians' education need to be adapted. There are some big, exciting challenges ahead.

AG: Absolutely; and it's constant because we tend to erect healthcare systems to deal with the problems of the past rather than the ones of the future. That's why, I think, the obesity epidemic has to some degree caught us a bit flatfooted. Sure, we had some experience dealing with kids with obesity. But the magnitude of the problem has grown so exponentially that, both in terms of healthcare systems and individual healthcare providers, we've been a bit overwhelmed. The obesity example reminds us that we need to continue to be thinking ahead about how morbidity and mortality change, and also about how to seize opportunities to intervene in those changes.

\section{MJH: Let me move on to the topic of research. I've heard you say that despite governmental fiscal constraints, we're at a historic moment in pediatric care and research. Can you elaborate on what you meant by that?}

AG: I believe we are at a historic moment because we have new tools to think about both children's health and, again, the lifelong developmental origins of health and diseases. I'm a bit biased, but I believe the genome sequence is an important contributor. For instance, it's difficult enough to comprehend that there are such things as epigenetic phenomena. But now we understand that one's environment in some ways gets the last laugh because it modifies your genome in various ways. We don't yet understand all the mechanisms of exactly how that happens, let alone exactly what environmental influences there are on our genes, yet we are able for the first time to really deal with the complexity of disease by asking those kinds of questions and thinking about those issues.

In medicine, we have always had to come up with artificially simplistic models. We tend to bifurcate everything; for example, you're either obese or you're not obese, you're healthy or you're not healthy, you have ADHD or you don't. We have taken that approach rather than, for instance, looking at the spectrum on which so much of human existence and well-being exist.

It's the same thing when it comes to genes and the environment. For years, the argument was, "Gee, is it nature or is it nurture?" Now, we've happily answered that question perfectly. It's neither nature nor nurture - it's both.

It's great that we now have the tools to be able to see that; but now it becomes a matter of developing other tools to really unwind those very complicated interrelationships between multiple genes and environmental factors. By environment, I don't just mean toxins and smokestacks, but also birth-community influences, social influences and so on.

For the first time ever, that's the story of kids' health, it's the story of kids' disease, and it's the story of kids' well-being. That is to say, it's a very complex kind of interplay. We've entered an era in which we can begin to do research that models this complexity and begins to dissect it. That's really just an incredible opportunity.

Then, when you add the ability for the first time really to 
begin to look at early development - whether during fetal existence or in childhood or maybe, to some degree, even pre-conception - to see how those factors influence health in adulthood ... well, that's just an incredible range of research opportunities.

MJH: It is an exciting and optimistic time as we think about children's health, both from where we've come and the trajectory we're on with both research and new knowledge and application. But as child health experts, leaders and policy makers, how do we ensure that we keep children's health a top priority? What are the types of issues we should be thinking about? How do we work either differently or more aggressively to take advantage of the momentum and the successes?

AG: It's a hugely important question, and I wish I had a better answer than I do. There's clearly not one answer to that issue of how to get the right prioritization for children's health or children's lives. I think we can see gradually that, while it's not a smooth curve and at times we go backwards, in general for

\section{I believe the vast majority of people} would say they're in favour of happy, healthy kids. But that's not the same as prioritizing it.

centuries now we have seen more and more of an elevation of children's issues. When NICHD was founded in the early 1960s, it didn't have a single pediatrician on staff.

Increasingly, we see children's lives as important for society to invest in for biomedical and other forms of research. That's the good news. The bad news is that the curve of the slope is not as steep as many of us would like to see.

There are lots of reasons for that. Some of them are political, in terms of who votes in elections and who doesn't. But I believe the solution lies in showing the value in terms of both social improvement and simple economics. Again, we need to demonstrate the contributions to child and adult health of investments in biomedical research.

The other, larger, more complex thing we need to do is to have multiple conversations in which we elevate children's lives. In doing that, people are pretty good about prioritizing the lives of their own children. As a society, we tend not to do generally as good a job of prioritizing the lives of children who are not our own.

If you were to ask, "Would you rather see healthy children or unhealthy children, and would you rather see happy children or unhappy children?" I believe the vast majority of people would say they're in favour of happy, healthy kids. But that's not the same as prioritizing it. That's not the same as saying that we as a society must refuse to let any child go to bed hungry each night.

We need to both talk about the value of children's lives and also actualize the fact that sometimes children literally cannot speak for themselves and, certainly, cannot fend for themselves.

We have a responsibility to society to make sure that kids have healthy, full, productive and safe lives. That kind of societal commitment takes more people talking about it and thinking more broadly, and being able to see beyond their own families. HQ

\section{One hundred experts One hundred presentations}

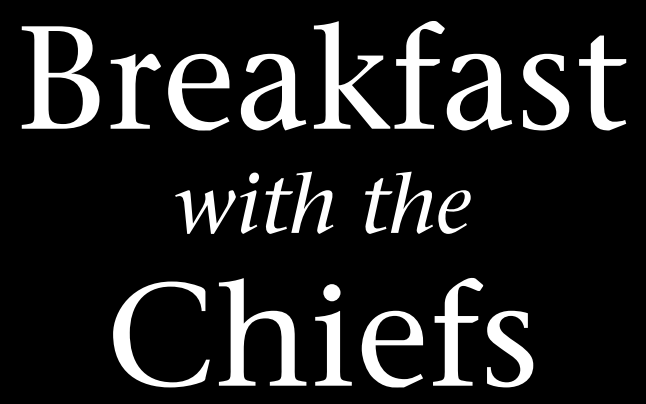

Breakfast with the Chiefs

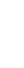
.

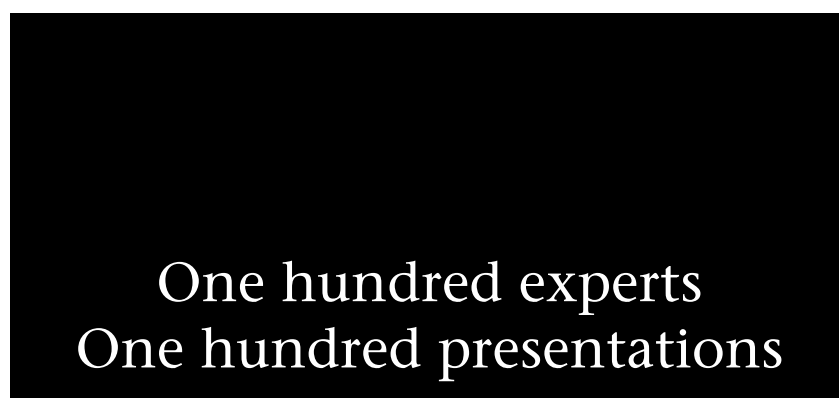

